Solution-focused brief therapy from the perspective of clients with long-term physical health conditions

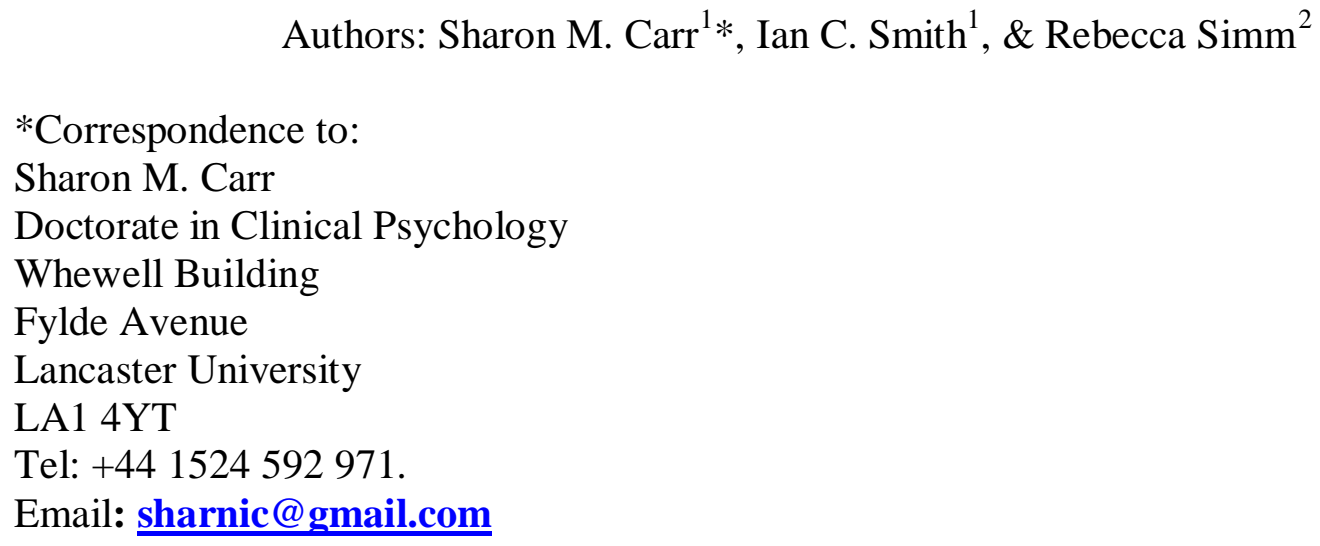

Word Count (excluding references, appendices, tables and figures): 2, 818

\footnotetext{
${ }^{1}$ Clinical Psychology Department, Institute for Health Research, Lancaster University, Lancaster, UK \& Lancashire Care NHS Foundation Trust

${ }^{2}$ Southport \& Ormskirk Hospital NHS Trust
} 


\begin{abstract}
As long-term physical health conditions are becoming increasingly prevalent in our society, interventions are needed to help individuals live as well as possible. The research explores participants' experiences of solution focused brief therapy (SFBT) with a view to determining helpful aspects of this. Eleven service users were interviewed, and interviews were analysed using thematic analysis (Braun \& Clarke, 2006). Participants’ responsibility for change and the strengths and resources they possessed were highlighted, along with the focus within therapy on goals. A number of specific SFBT techniques that were perceived as helpful during therapy were described such as reframing and competence talk, as well as other factors that enabled engagement with the psychologist.
\end{abstract}




\section{Solution focused brief therapy from the perspective of clients with long-term physical}

\section{health conditions}

A diagnosis of a long-term physical health condition can be a devastating experience for individuals (Forshaw, 2002). Between 20-25 percent of individuals with long-term conditions (LTCs) experience symptoms of psychological distress significant enough to necessitate intervention (White, 2001). Anxiety and depression are common reactions to LTCs among stroke patients, cancer patients, and those experiencing chronic pain (Gormsen, Rosenberg, Bach, \& Jensen, 2010; Taylor, 2006), and can exacerbate the risk and course of several LTCs, impact on rehabilitation and reduce health-related quality of life. As such, they are an important focus for psychological intervention.

In the UK National Health Service, short-term therapeutic interventions are recommended for individuals with LTCs, such as solution focused brief therapy (SFBT) (NICE, 2009). The aim of SFBT is to help individuals recognise successes in their lives and achieve preferred outcome by discussing solutions, despite the presence of problems or difficulties (Froerer, Smock, \& Seedall, 2009; O'Connell, 2001). Within SFBT, the focus is on facilitating change and increasing hope for future change by recognising and expanding individual's resources, and motivating and empowering individuals (O'Connell, 2005a).

The links between adjustment and dispositional optimism (the tendency to have positive expectations or hopes for the future) have been explored by Dennison, Moss-Morris, and Chalder (2009). The authors found that optimism was associated with lower depression, anxiety, and negative affect, and better physical, social, and psychological adjustment in individuals. Furthermore, they suggested that finding solutions to achieve valued goals and developing the motivation to see these solutions through could increase psychological wellbeing (Dennison et al., 2009). As such, retaining hopes for the future and actively trying to achieve them, tenets of SFBT , is important to improve psychological well-being. 
While it has been applied to a range of presenting problems, the use of SFBT with clients with LTCs remains an under-researched area (Viner, Christie, Taylor, \& Hey, 2003). As a result, qualitative research methods are indicated to enable theories to be developed and understanding to be enriched (Elliott, Fischer, \& Rennie, 1999). The aim of the research was to explore the use of SFBT with clients with LTCs, to gain an understanding of their experience of therapy and the aspects perceived as helpful.

\section{Method}

\section{Participants}

Eleven participants were recruited from a clinical health psychology department in the North of England. Two clinical psychologists (one male with 18 years professional experience, one female with six years professional experience) within this service offer appointments to adults who are experiencing psychological difficulties associated with having a long-term physical health condition. Participants recruited to the study were experiencing one of the following LTCs: Parkinson's disease, cancer, chronic pain, lung

disease, or Hepatitis B. Participants were four men and seven women, ranging in age from 35 to 85 years $($ mean $=54.1$ years $)$. Participants had attended between one and 12 sessions of SFBT, provided on an individual or group basis.

\section{Procedure}

The research used a qualitative phenomenological approach to explore participants’ lived experiences of SFBT and the meanings attributed to the therapy. The underlying assumption guiding the research was that the subjective experience of participants and the recurring patterns among a group of participants could be captured by the use of an openended interview, and that this would provide information about the important aspects of SFBT amongst this particular group of participants. A semi-structured interview schedule 
was used to guide the exploration of various aspects of participants' experiences, and each participant completed one interview.

The research was approved by a local NHS research ethics committee. The inclusion criterion used to recruit participants from the service was that clients had attended for their most recent session of SFBT within the past 3 to 12 months. Potential participants were sent a letter by the service inviting them to take part in the research by contacting the first author, who arranged and conducted a one-hour face-to-face interview with each participant. Informed consent was obtained from participants prior to the interview.

\section{Analysis}

Inductive thematic analysis was used to allow participants' experiences, meaning, and reality to be described in detail (Braun \& Clarke, 2006; Kyriacou, Easter, \& Tchanturia, 2009). The research stemmed from a constructionist viewpoint, focusing on examining the way participants described their experiences and the meanings attributed to events within the therapy. The use of thematic analysis allowed patterns or themes to be identified, analysed, and reported across the entire set of interviews, rather than within individual interviews (Braun \& Clarke, 2006).

An idiographic approach to the analysis was taken with the most data-rich interview being chosen to begin the process of analysis, and initial codes developed from this by the first author. The phases of analysis described by Braun and Clarke (2006) were used as a guide. Transcripts were referred to repeatedly throughout the analysis phase in an attempt to ensure that the data were represented appropriately. The initial codes outlined focused on the semantic content of the data and these developed into more interpretive themes as the phases of analysis progressed. Themes were defined, edited and expanded as additional quotations were added, themes were clustered and linked, and new themes were created to fully explore 
and interpret participants' experiences (Dennison, Stanbrook, Moss-Morris, Yardley, \& Chalder, 2010).

Once an initial set of themes was generated, further refinement and validation took place through discussions between the three authors. The remaining themes were then “defined and refined” (Braun \& Clarke, 2006, p. 92), by defining what the theme referred to and using quotations to reflect the theme. The validity of the themes and the plausibility of the emergent codes and themes were discussed within the group at each stage.

\section{Results and Discussion}

Four themes were identified: owning the therapy; psychologist on my side; looking forwards not backwards; and importance of communication about and during the therapy.

\section{Owning the therapy}

This theme describes the importance participants attributed to their contribution throughout the therapy and ownership of the changes made. As the participants initiated change for themselves, they described feeling empowered and more in control of their difficulties. Participants felt that the way the psychologist spoke enabled them to work out their own difficulties, leaving them feeling more in control. The psychologist helped participants to recognise their responsibility for change through the reflections made, the way questions were asked and the summaries offered by the psychologist. Participants reported that they were required to think about their difficulties differently, which enabled them to interact with and manage their difficulties in a new way. As a result, participants reported coming up with their own solutions, and felt more confident to do so after seeing the psychologist.

However, a number of participants also expressed frustration that the psychologist was not more active in the therapy. At times, participants felt they needed the psychologist to offer solutions rather than helping them to come up with the answers themselves. 
I kind of wanted [psychologist] to tell me, or give me some examples, or give me some way of being able to solve it myself, or someone solving it for me ... which I know isn’t the best way of doing it... but when you're so exhausted, you want, you just wanted answers (P3).

The participants were able to express this frustration with the psychologist - "like me and [psychologist] jousted... but [psychologist] was strong enough to deal with me” (P7) demonstrating that they had developed a good working relationship. While this way of working could be challenging for participants at times, they recognised that it was more helpful in the long run.

Despite participants generally attending a small number of appointments with the psychologist, they acknowledged that there was little more that could be done in additional sessions as it was their responsibility to make the changes discussed. Furthermore, participants described making changes after a small amount of contact with the psychologist. In some cases changes were seen after one appointment, suggesting that they had received sufficient support and assistance from the psychologist to be able to move forwards in their lives by themselves.

The reflections offered, the specific way questions were asked and the summaries offered by the psychologist helped participants to see their difficulties from a new perspective, such that solutions to these difficulties became apparent to them. Through this process, participants felt as though it was their contribution to the therapy that enabled changes, as they uncovered their own solutions to difficulties.

\section{Psychologist on my side}

All of the participants described the importance of being able to "offload" (P9) to the psychologist, and the psychologist's qualities which helped them to do this. Particularly important were the non-judgmental stance and relaxing manner of the psychologist. The 
process of talking in itself was helpful for some participants as they felt unable to share their worries and fears with family and friends. However, participants recognised that talking about things did not in itself have an impact on their difficulties; what was useful was the psychologist’s ability to draw out participants' strengths and resources to cope. The psychologist focused on these aspects and reinforced them, leaving participants believing that they were "on [my] side” (P5). This provided participants with the strength needed to face their LTC and other professionals involved in their care: “It’s empowering, because y'know you've got some back up, you've got a, for want of a better word, a shrink saying you're alright, know what I mean? So it’s a bit of back up” (P7).

The resulting increase in participants' confidence meant that they were able to use existing skills in new ways and felt better able to manage their illness following therapy. What had changed was that, eh. I certainly had the confidence to cope... and I was able to make a decision... and I, I'd never made a decision like that... but I made it, and I don’t think I would have been able to make if it I hadn’t have felt, the confidence that I got when I’d finished with [psychologist] (P9).

The two themes outlined above describe a number of common practices within SFBT _ “reframing” and “competence talk” (O’Connell, 2005b, p.34-35), “reflecting” . These practices involve the psychologist helping participants to see their difficulties in a different light, and identifying and reinforcing their strengths and resources. Walker, Lindner, and Noonan (2009) have highlighted that individuals with LTCs commonly experience a loss of control due to their condition. Participants in the present research had designed their own solutions and felt responsible for any changes that were made both during and after therapy, indicating that they experienced a degree of control over their difficulties.

These results support Wehr's (2010) findings that adopting solution-focussed interventions could improve individuals' mood and self-confidence, with participants in the 
current study feeling better able to manage their illness and make decisions following therapy. The two main aspects of SFBT suggested to be most beneficial within the current research are the way in which questions were posed by the psychologist and the focus on highlighting participants’ strengths.

\section{Looking forwards not backwards}

Participants described their experience of SBT as different from previous experiences of psychological therapy, as the psychologist was interested in finding out about the participants' wider goals in life, not limited to those within therapy. Asking questions about what participants wanted to achieve in life instead of solely focusing on their difficulties helped them to feel hopeful for the future, and encouraged them to think about what was important to them. As a result, therapy was described by a number of participants to be the start of their journey back to where they wanted to be in life.

I think it gave me, unconsciously, the thought that “... I'm planning something in the future”. So at the time plans for in the future was quite a good thing to do, cos it gave you a more positive thing (P9).

Reiter (2010) proposed that the expectation for change can be developed by focusing on goals within therapy, and that this can engender a sense of hope and optimism for the future. In addition, the process of reviewing movement towards goals can revitalise clients and enhance their belief in themselves (Reiter, 2010). In line with these suggestions, participants in the current research described feeling hopeful, both about their future and the prospect of continued change, following discussions about their aspirations with the psychologist.

de Shazer suggests that clients within SFBT have a sense of responsibility over goals as they involve the clients' "hard work" (1991, p.112). This idea was reflected by participants' sense of responsibility over therapy and the changes made during and after 
therapy. Participants also described the therapy as the start of their journey, reflecting de Shazer's (1991) suggestion that therapy represents the "start of something" rather than the “end of something” (1991, p.112). Furthermore, participants within the current study reported an increase in well-being as a result of finding their own solutions to difficulties, in line with Dennison et al.’s (2009) findings.

Scheier \& Carver (1992) suggest that optimism has a positive impact on physical well-being, whereby optimists recover and return to "normalised” functioning quicker than pessimists (p.207). They propose that using problem-focused coping strategies and focusing on goals enables individuals to remain optimistic when faced with challenges. However, by adopting a goal-focused rather than problem-focused strategy within SFBT the general wellbeing of participants within the current research had improved, highlighting that strategies other than problem-focused ones can lead to increased feelings of hope and well-being.

\section{Importance of communication about and during the therapy}

Communication about and during the therapy was important to participants. Despite the service providing an information leaflet and discussion with the psychologist about what to expect, participants' expectations were not met by the psychologist at times: "I felt like I was getting a rat on with [psychologist] cos I had expectations of [them] that weren't being fulfilled in my own mind...” (P7).

The communications received from the psychologist after each session, in the form of a letter, were valued by participants. These letters provided reminders of what had been talked about in therapy and of participants' goals for their next appointment. As such, it was important that these letters were received promptly after sessions and were written in plain English.

Whereas much quantitative literature within clinical health psychology has focused on the process of acceptance and adjustment to LTCs (e.g., Forshaw, 2002; McCracken \& Zhao- 
O’Brien, 2010; Stanton, Revenson, \& Tennen, 2007), this was not a major factor for participants in the current study. A number of participants spoke about their conflict between acknowledging their illness and accepting the limitations associated with it, as they believed it would not be possible for them to continue living their lives the way they wanted if they accepted their limitations. Scheier and Carver (1992) have highlighted the importance of accepting challenges, particularly when they are recurring or chronic, to facilitate individuals' appropriate coping. In contrast, participants in this study emphasised the importance of acknowledging but not necessarily accepting their condition, and did not experience negative consequences as a result. This suggests that acceptance of limitations may not be an essential stage individuals have to go through for individuals to feel like they can cope effectively with their LTC.

\section{Challenges and areas for future research}

One of the challenges encountered during the research was participants' ability to recall specific experiences within therapy, as a number of participants stated that they were struggling to recall specific aspects of their therapy with the psychologist. Nonetheless, participants were able to name and describe various aspects of their therapy that they perceived as helpful and unhelpful.

Future research measuring outcomes for individuals with LTCs following SFBT would be useful, for example focusing on participants' confidence and hopefulness. Further exploration of the experience of SFBT with different client groups would allow greater understanding of the specific aspects of SFBT that individuals find useful, as the aspects of therapy described by the participants may be particular to their experiences of a LTC.

\section{Conclusion}

The current research explored the use of SFBT with clients with LTCs and their experiences of therapy. Four themes were highlighted in participants accounts, outlining a 
number of aspects which were important for participants during their therapy. In particular, the way the psychologist worked with participants increased their feelings of empowerment, control and confidence, and enabled them to uncover their own solutions to difficulties and feel better able to manage their illness following therapy. This was helped by the psychologist's approach which reinforced participants' strengths and resources to cope, helping them to focus on what they wanted to achieve in their life, in turn engendering hope for their future. Participants also spoke about the conflict they perceived between accepting and acknowledging their illness, and their belief that acceptance was not necessary. Supporting other health professionals to take a psychologically sound approach such as SFBT within this kind of care setting could therefore perhaps further enhance patient care and outcomes, and help to improve well-being. 


\section{References}

Braun, V., \& Clarke, V. (2006). Using thematic analysis in psychology. Qualitative Research in Psychology, 3, 77-101. doi: 10.1191/1478088706qp063oa

de Shazer, S. (1991). Putting difference to work. New York: Norton.

Dennison, L., Moss-Morris, R., \& Chalder, T. (2009). A review of psychological correlates of adjustment in patients with multiple sclerosis. Clinical Psychology Review, 29, 141153. doi: 10.1016/j.cpr.2008.12.001

Dennison, L., Stanbrook, R., Moss-Morris, R., Yardley, L., \& Chalder, T. (2010). Cognitive behavioural therapy and psycho-education for chronic fatigue syndrome in young people: Reflections from the families' perspective. British Journal of Health Psychology, 15, 167-183. doi: 10.1348/135910709x440034

Elliott, R., Fischer, C. T., \& Rennie, D. L. (1999). Evolving guidelines for publication of qualitative research studies in psychology and related fields. British Journal of Clinical Psychology, 38, 215-229. http://www.integentaconnect.com/content/bpsoc/bjcp

Forshaw, M. (2002). Essential Health Psychology. London: Arnold.

Froerer, A. S., Smock, S. A., \& Seedall, R. B. (2009). Solution-focused group work: Collaborating with clients diagnosed with HIV/AIDS. Journal of Family Psychotherapy, 20, 13-27. doi: 10.1080/08975350802716475

Gormsen, L., Rosenberg, R., Bach, F. W., \& Jensen, T. S. (2010). Depression, anxiety, health-related quality of life and pain in patients with chronic fibromyalgia and neuropathic pain. European Journal of Pain, 14, 127.e121-e128. doi: 10.1016/j.ejpain.2009.03.010 
Kyriacou, O., Easter, A., \& Tchanturia, K. (2009). Comparing views of patients, parents, and clinicians on emotions in anorexia A qualitative study. Journal of Health Psychology, 14, 843-854. doi: 10.1177/1359105309340977

McCracken, L. M., \& Zhao-O'Brien, J. (2010). General psychological acceptance and chronic pain: There is more to accept than the pain itself. European Journal of Pain, 14, 170175. doi: 10.1016/j.ejpain.2009.03.004

NICE. (2009). Depression in adults with a chronic physical health problem: Treatment and management.

O'Connell, B. (2001). Solution focused stress counselling. London: Continuum.

O'Connell, B. (2005a). Introduction to the solution-focused approach. In B. O'Connell (Ed.), Solution-focused therapy (2nd ed., pp. 1-11). London: Sage Publications Ltd.

O'Connell, B. (2005b). Solution-focused therapy (2nd ed.). London: Sage Publications Ltd.

Reiter, M. D. (2010). Hope and expectancy in solution-focused brief therapy. Journal of Family Psychotherapy, 21, 132-148. doi: 10.1080/08975353.2010.483653

Scheier, M. F., \& Carver, C. S. (1992). Effects of optimism on psychological and physical well-being: Theoretical overview and empirical update. Cognitive Therapy and Research, 16, 201-228. http://www.springer.com/medicine/journal/10608

Stanton, A. L., Revenson, T. A., \& Tennen, H. (2007). Health psychology: Psychological adjustment to chronic disease. Annual Review of Psychology, 58, 565-592. doi: 10.1146/annurev.psych.58.110405.085615

Taylor, S. E. (2006). Health psychology (6th ed.). New York: McGraw-Hill.

Viner, R. M., Christie, D., Taylor, V., \& Hey, S. (2003). Motivational/solution-focused intervention improves HbA[sub 1c] in adolescents with Type 1 diabetes: a pilot study. Diabetic Medicine, 20, 739. doi: 10.1046/j.1464-5491.2003.00995.x 
Walker, K., Lindner, H., \& Noonan, M. (2009). The role of coping in the relationship between depression and illness severity in chronic fatigue syndrome. Journal of Allied Health, 39, 91-99. http://www.ingentaconnect.com/content/asahp/jah

Wehr, T. (2010). The phenomenology of exception times: Qualitative differences between problem-focussed and solution-focussed interventions. Applied Cognitive Psychology, 24, 467-480. doi: 10.1002/acp.1562

White, C. A. (2001). Cognitive behaviour therapy for chronic medical problems: A guide to assessment and treatment in practice. West Sussex, England: Wiley 